\title{
ВЕРБАЛИЗАЦИЯ ЛИНГВОКУЛЬТУРОЛОГИЧЕСКОГО КОНЦЕПТА «ЖЕНЩИНА» (НА ОСНОВЕ ПРОИЗВЕДЕНИЙ СОФИ КИНСЕЛЛЫ)
}

\author{
Verbalization of the Linguoculturological Concept "Woman" \\ (on the Basis of Sophie Kinsella Novels)
}

\begin{abstract}
Keywords: linguoculturological concept, linguoculturology, novel, verbalization of concept, representation of concept
\end{abstract}

Contact: Казахский университет международных отношений и мировых языков имени Абылай Хана; fashion_photographer@mail.ru

Концепт является одним из самых широко и часто рассматриваемых терминов современной лингвистической науки. Концепт не имеет точного определения, каждый раз он интерпретируется с разной точки зрения: с точки зрения науки и ученого-лингвиста рассматривающего его. В данной статье мы придерживаемся определения концепта, предложенного Ю. С. Степановым, что концепт - это как бы сгусток культуры в сознании человека; то, в виде чего культура входит в ментальный мир человека (Степанов 2004: 42). В лингвистике, согласно многим советским и иностранным авторам, концепт является одним из основных элементов когнитивной лингвистики, который несет в себе ценные и культурные коннотации определенного слова или понятия.

Лингвокультурология - это взаимодействие языка и культуры. Наравне с концептом, данный термин также является одним из широко распространенных и используемых в современной отечественной и зарубежной лингвистике. Согласно многим ученым, лингвокультурология устанавливает способы и средства хранения культурной информации в языковой семантике (Антропова, Бурдуковская 2013: 69).

Таким образом, концепт это соединение языка и культуры, так как с лингвистической стороны, концепт вербализуется через определенные лексические единицы, которые передают значение понятия «женщина», с лингвокультурологической стороны, концепт отражает взгляды, верования 
и отношения определенной нации, которые имеют определенные ассоциации, которые возникают в сознании людей принадлежащих к определенной культуре.

Целью данной статьи является изучение различных способов вербализации концепта «женщина» на основе выбранных автором британских произведений Софи Кинселлы, чтобы выявить лингвокультурологический образ женщины в современном британском обществе.

В данной статье рассматривается лингвокультурологический концепт «женщина», где автор попытается выявить образ современной женщины через различные средства ее вербализации. Данный концепт является одним из часто упоминаемых, рассматриваемых и актуальных, так как женщина - это часть нашей жизни. Концепт может репрезентироваться различными способами.

Так, например, ученые 3. Д. Попова и И. А. Стернин наиболее четко определили в своем исследовании те языковые средства, которые формируют номинативное поле концепта и тем самым выступают средствами его вербализации: 1) непосредственные номинации концепта; 2) производные номинации концепта; 3) лексические единицы, выступающие однокоренными словами к номинантам концепта; 4) симиляры; 5) контекстуальные синонимы; 6) окказиональные индивидуально-авторские номинации; 7) устойчивые словосочетания, синонимичные непосредственному номинанту концепта; 8) фразеосочетания, 9) паремии (пословицы, поговорки, афоризмы); 10) метафорические номинации; 11) устойчивые сравнения с ключевым словом; 12) свободные словосочетания, номинирующие те или иные признаки концепта (Попова, Стернин 2007: 69-71).

А. В. Рудакова также полагает, что в языке концепт может выражаться с помощью различных языковых средств: 1) готовыми лексемами и фразеосочетаниями из состава лексико-фразеологической системы языка; 2) свободными словосочетаниями; 3) структурными и позиционными схемами предложений; 4) текстами и совокупностями текстов (Рудакова 2004: 48).

Исходя из того, что было сказано учеными выше, мы можем прийти к выводу, что концепт может репрезентироваться различными способами. В нашей статье за основу анализа было взято два романа Софи Кинселлы «Тайный мир шопоголика» и «Богиня на кухне», чтобы выявить образ лингвокультурологического концепта «женщина». Основными средствами вербализации концепта «женщина» являются лексические единицы, выражения и целые предложения, которые эксплицировали тот или иной элемент вышеупомянутого концепта. 
Во многих романах Софи Кинселлы, также как и в большинстве романов ее современников, на протяжении всего произведения образ женщины меняется, меняется отношение к ней окружающих и главное ее отношение к самой себе. Это вызвано различными факторами и событиями, происходящими в ее жизни. В большинстве случаев, если изначально образ воспринимался отрицательно как ею самой, так и окружающими, как это происходит в романе Гейл Ханимен «Элеанор Олифант в полном порядке», то, ближе к концу романа, она меняется в лучшую сторону, как во внешности, так и внутренне. Помочь главным героиням в этом помогают близкие ей люди.

Так, например, в вышеупомянутом романе Гейл Ханимен «Олифант в полном порядке», в начале романа создается образ брошенной всеми молодой женщины, которая много времени проводит на работе, не ведет здоровый образ жизни, не занимается спортом, не проводит время с родными и друзьями, которых у нее нет и употребляет много спиртного, дабы заглушить свою внутреннюю боль от безразличия со стороны коллег, которое выражается в насмешках с их стороны в сторону внешнего вида главной героини. Она мирится с этим образом и не пытается что-то сделать, чтобы как-то измениться. Только, вследствие любви к одному мужчине и знакомства с коллегой на работе, который впоследствии становится ее близким другом, она меняется, сама того не сознавая, как внешне так и внутренне.

Таким образом, как и во многих романах прошлого и нынешнего столетия, такие чувства как любовь и дружба, которые являются постоянными проводниками в жизни героинь и героев романов, меняют главную героиню в лучшую сторону.

Так же происходит и в двух романах Софи Кинселлы, за основу которых мы взяли для изучения способов репрезентации лингокультурологического концепта «женщина», которые помогут нам создать одни из образов современной женщины.

В романах «Тайный мир шопоголика» и «Богиня на кухне» показывается и раскрывается современная женщина 21 века со всеми чертами общества, присущими нынешнему веку, которые влияют на создание образа современной женщины.

В романе «Тайный мир шопоголика» современная женщина получила образование в сфере журналистики. Она хочет быть востребованной и популярной в своей сфере, что вербализуется в следующем контексте: “I'm a journalist on a financial magazine. I'm paid to tell other people how to organize their 
money”. Она - самодостаточна, не зависит и живет отдельно от родителей. Также как и в современном мире, она еще не имеет достаточных средств на покупку собственного жилья, поэтому, она снимает квартиру со своей лучшей подругой: "This is why I love sharing a flat with Suze. Julia, my old flatmate, would have wrinkled her brow and said, "Denny and who?" or, "That's a lot of money for a scarf." But Suze completely and utterly understands. If anything, she's worse than me". Многие современные женщины увлекаются модой и следят за последними модными новинками и стремятся прибрести эту незамедлительно, как это часто делает героиня этого романа Ребекка Блумвуд. Как и многие современные девушки и женщины, она много времени уделяет своему внешнему виду, применяет много сил и средств, для того, чтобы ухаживать за своим телом и внешним видом: “I'll get that swirly coat in Whistles. And some black high-heeled boots from Pied \& Terre. Maybe I'll go on holiday”. Она увлекается модой, живет ею и хочет работать в сфере модной журналистики, так как она с детства мечтала об этом: “Of course, being a financial journalist is not the career I always wanted. No one who writes about personal finance ever meant to do it". Также, она является шопоголиком, большую часть своей зарплаты она тратит на покупку ненужных вещей. Ребекка Блумвуд страдает шопоголизмом: "There is no question. I have to have this scarf. I have to have it. It makes my eyes look bigger, it makes my haircut look more expensive, it makes me look like a different person. I'll be able to wear it with everything. People will refer to me as the Girl in the Denny and George scarf".

Что касается внутренних характеристик главной героини, автор приписывает ей такие черты как инфантильность, невнимательность, мечтательность. Она часто витает в облаках, представляя какой будет ее жизнь, если она выиграет в лотерею, расплатится с долгами и будет жить так как ей хочется: “Тhe newspaper's open in front of me at the property section and I carelessly pick it up to peruse expensive houses. Where shall I live? Chelsea? Notting Hill? Mayfair? Belgravia, I read. Magnificent seven-bedroom detached house with staff annex and mature garden. Well, that sounds all right".

В начале романа мы видим образ инфантильной, ни к чему не стремящейся девушки, которая только и думает о том, чтобы приобрести новую модную вещь. Ради этого она даже идет на обман, чтобы купить последний шарф от марки «Денни и Джордж». Она неспособна взять на себя ответственность каждый раз, скрываясь от банкира, который настойчиво требует ее вернуть большую сумму денег, которую она задолжала банку. Ребекке приходится придумывать ложь за ложью, чтобы скрыть тот факт, что она не способна вернуть долг. 
В современном романе также присутствует новый аспект - сексуальный, употребляющийся во многих современных романах, но не так часто встречающийся в романах прошлых веков в связи с тем, что в те времена упоминание женщины в этом аспекте было непозволительным и неправильным с моральной точки зрения. В современном обществе, женщина имеет право не только на то, чтобы получить образование и достойную, высокооплачиваемую работу, но и право на любовные и сексуальные отношения, о которых открыто говорится в данном романе. Современная женщина открыто говорит о своих партнерах и сексе: "Bex, you man-eater!. His mouth is on mine, gently parting my lips, and I feel a white-hot dart of excitement. His hands are running down my back and cupping my bottom, fingering under the hem of my skirt. And then he pulls me tightly toward him, and suddenly I'm finding it hard to breathe".

Также, ее слова и действия не воспринимают всерьез, ее считают простой деревенской девушкой: “I'm the scatty girl who gets things wrong and makes people laugh. The girl who didn't know SBG and Rutland Bank had merged. The girl no one would ever think of taking seriously".

В этом произведении обыгрывается важная тема для современного общества, являющееся в то же время одной из ее проблем - консьюмеризм. Ребекка Блумвуд является олицетворением многих современных женщин и мужчин, которые страдают потребительским отношением ко всему. Согласно исследованиям, Великобритания наряду со многими другими европейскими странами имеет данную проблему, около 70\% людей страдают им, не представляя к каким психологическим проблемам это может привести.

Ближе к концу произведения, наблюдается изменение характера главной героини, где мы отчетливо видим, что она осознает свою проблему, что ей хочется действительно бороться с ней, не как раньше, когда она жила в ложных иллюзиях, что выиграет в лотерею или выйдет замуж за богатого принца и расплатится с долгами. Оставшись наедине с самой собой, в доме родителей, и пытаясь помочь старым друзьям родителей, которые оказались обманутыми вкладчиками одно из известных Ребекке банков, она предпринимает попытку помочь им, написав статью для одного из финансовых журналов. Изначальной целью героини написания статьи была подработка, для того, чтобы накопить сумму для оплаты долга, несмотря на то, что ей не нравится сфера финансовой журналистики, и она всегда мечтала от нее избавиться, так как, она считает, что ничего не смыслит в финансах. Тем не менее, у нее получилось преуспеть и завлечь читателей своей статьей: "The editor's really going for this series, so if you come up with any more stories like this just give me a shout. I like your style. Just right for the Daily World”. 
Пытаясь разрешить проблему, она, сама того не сознавая, пришла к выводу, что то, чем она занималась все это время, является ее делом жизни, которое стоит развивать в дальнейшем: "I've got the right style for the Daily World! Ha! At last I've found my niche!"”.

Осознание проблемы и попытка ее решения приводит к успеху главной героини. На телевидении ей предлагают дополнительную работу в качестве финансового консультанта: "We thought you did tremendously well today, I've spoken to Emma and Rory and our senior producer - she pauses for effect - and they'd all like to see you back on the show". Также, она преуспевает в любви, потому что она становится заметной, она больше не является очередным работником, у нее горят глаза от ее дела. Героиня и окружающие ее люди чувствуют, что изменилась: "You're so . . . different. It's frightening. Yes well. I reach for a white shirt and smile at her. Maybe I've changed". Сама героиня после осмысления о своем предназначении в жизни, после того, как она поняла, чем ей нужно заниматься в жизни, приходит к выводу, что она изменилась: "It seems like about a million years since I was here last, and I feel like a completely different person. I've grown up. Or changed. Or something.". После переосмысления ценностей, она меняет свое отношение к деньгам: “I'm going to sort my life out and keep my finances in order from now on. I've completely and utterly changed my attitude toward money".

Таким образом, автор хочет подчеркнуть и показать, что современная женщина только тогда достигает успеха, когда она понимает и знает, чего хочет добиться и чему хочет посвятить себя в этой жизни. Героиня изменяется благодаря тому, что понимает о своей стезе в жизни. Автор хочет сделать из своей героини личность, чтобы показать всем женщинам мира, что каждая женщина достойна любви, дружбы и успеха, что в совокупности приводит ее на вершину.

В то время как в романе «Богиня на кухне» концепт «женщина» в лице главной героини также претерпевает изменения как внешне, так и внутренне, когда оказывается под влиянием любви. Данный образ полностью отображает образ современной женщины: одинокой, трудолюбивой, работящей женщины, у которой нет времени на отношения с семьей, друзьями и, тем более, с любовниками. Как и большинство современных женщин, Саманта полностью отдает себя работе, находясь на ней не 8 часов в день, а по 14, а то и больше: “On average, how many hours do you spend in the office every day? 14. 12. 8. It depends".

Говоря о чертах характера главной героини, которая является своего рода олицетворением большинства современных женщин, в начале романа автор наделил ее такими отрицательными чертами как невнимательность, быть 
в постоянной спешке: "I did mention that I'm in a bit of a hurry", напряженность: "So sometimes I do feel a bit tense", постоянная физическая и моральная усталость: "no matter how exhausted I am...", что вызвано ее постоянным присутствием и мыслями только о работе: "Your job is obviously very pressured." I thrive under pressure," I explain.

Современные романы изобилуют таким новым элементом развития технологий 21 века, как социальные сети, которые заполонили жизнь любого человека. C одной стороны, они упрощают нашу жизнь, делая возможным общаться на расстоянии, работая и приобретая всевозможные вещи, не выходя из дома, в то же самое время, они усложняют нашу жизнь, делая человека зависимым от них. Человек не может представить себе и дня без социальных сетей. Главная героиня так же зависима от них, так как в них находится вся ее работа. Автор употребляет сравнение, сравнивая социальные сети с другими пагубными привычками, как алкоголизм, наркомания и потребление кофеина: “Could I possibly send a quick e-mail? You're here to relax. To take a moment for yourself. Not to send e-mails. E-mail's an obsession! An addiction! As evil as alcohol. Or caffeine".

Вышеупомянутые отрицательные черты характера женщины связаны с определенными условиями и ситуациями, в которых может оказаться любая современная женщина. Чтобы добиться успеха на работе, главной героине приходится усердно работать, не покладая рук, даже пренебрегая своей личной жизнью: "This is the crucial part: I was single", даже не давая возможности себе полностью насладиться сексуальной жизнью: “But two years ago I dated a senior partner from Berry Forbes. His name was Jacob and he worked on huge international mergers, and he had even less time than I did. By the end, we'd honed our routine to about six minutes, which would have been quite handy if we were billing each other. He would make me come - and I would make him come. And then we'd check our e-mails." Главной героине приходится работать намного усерднее, чтобы доказать, что она достойна того, чтобы быть назначенной на место старшего партнера: "Partner of one of the biggest law firms o the country. He only thing I've ever wanted, ever", даже пренебрегая здоровьем: "U haven't had a proper meal for a week." и свободным временем: “A City lawyer who hasn't been on holiday for two years doesn't have a tan”. В современном обществе чаще всего женщине приходится выбирать между успешной личной жизнью и успешной работой, отдавая предпочтение последнему, как это сделала Саманта.

Этот роман отражает современное видение современной женщины, согласно которому женщина - трудоголик, проводящей много времени на работе, у которой нет времени, чтобы приготовить себе завтрак или ужин. Также, мнение 
матери Саманты отражает феминистический взгляд многих женщин о равноправии на работе и в домашних делах: "She disapproves of women taking the name of their husband. She also disapproves of women staying at home, cooking, cleaning, or learning to type, and thinks all women should earn more than their husbands because they're naturally brighter".

Тем не менее, главная героиня является динамической героиней, изменяясь на протяжении всего романа, меняя свои привычки и предназначение в жизни. В этом романе, в отличие от предыдущего, главная героиня меняется благодаря любви. После того, как она теряет свою работу из-за сделанной ею ошибки, она, из-за случайного стечения обстоятельств оказывается нанята домохозяйкой в доме одной обеспеченной семьи. Там, ей приходится столкнуться с реалиями жизни, с тем, что ей нужно полностью постичь то, с чем до этого ей не приходилось сталкиваться. Именно здесь автор показывает те ситуации, которых она избегала в своей предудыщей жизни, так как она была полностью отдана своей работе. Например, она не умела ни готовить простые блюда: "I never really did home economics at school." I explain. "I never really learned how to make meals"», ни включать стиральную машину и даже пылесос: “I really don't have time for this. I mean, vacuum bags. I don't even know what they look like, for God's sake", ни гладить: “I can't iron a shirt. I've never used an iron in my life.", ни заправлять кровати: «I cannot make this bed», ни протирать полы.

Тем не менее, под давлением обстоятельств, главной героине приходится подстроиться под новый ритм жизни и научиться выполнять все домашние дела успешно. Так, например, ей удалось научиться готовить, чему она сама удивлена: "I cannot believe I'm making gravy. Making gravy. And - like everything I've learned to make in this amazing kitchen - it's working. The ingredients are obeying". На пути к приобретению новых навыков, Саманта даже не осознавала, что влюбилась. Любовь к Натаниэлю заставила ее измениться. Она хотела делать все с любовью и теплотой. Испытав любовь, она начинает обращать внимание на свой внешний вид и тело, на что раньше у нее категорически не было времени: "I walk over to the mirror and, for the first time since I've arrived here, examine my appearance with an honest, unflinching eye". Автор создает динамический образ женщины используя определенные лексические средства речи, чтобы показать, что женщина может меняться, что женщина может преуспеть не только на кухне, но и на работе, что любовь может изменить человека: "My life has changed, and I'm changing with it", изменить его представление о предназначении в жизни, как это произошло с Самантой: 'I'm happy in my job. I'm happy in this village. I'm happy with you. I just want everything to stay the same". 
Таким образом, в романе «Богиня на кухне» основные средства вербализации концепта «женщина» выражают изменения в характере женщины. Одним из основных факторов к изменению является любовь, которая сподвигнула ее на изменения своего образа жизни и понимание своего предназначения в жизни.

Проанализировав лексические средства выражения лингвокультурологического концепта «женщина» согласно романам Софи Кинселлы, автор статьи пришел к выводу, что лингвокультурологический концепт «женщина» тесно взаимосвязан с такими элементами как «черты характера», в которых, в начале романа чаще всего превалируют отрицательные черты под воздействием внешних обстоятельств, таких как самообман (иллюзия) или работа, как, например, в романе «Тайны мир шопоголика», где главная героиня отрицает, что страдает консьюмеризмом и шопоголизмом, продолжая потреблять большое ненужное количество вещей, и в романе «Богиня на кухне», где главная героиня большую часть времени проводит на работе, в погоне за успехом, забыв о своем эмоциональном и физическом здоровье, о личной жизни, о внешнем виде, о первоначальном предназначении женщины, но, постоянно изменяющихся на протяжении романа под воздействием любви и дружбы, которые помогают главным героиням приобрести свое предназначение в жизни и любовь близких и к самой себе. Данные романы доказывают, что современная британская женщина может совмещать в себе несколько качеств, она - модная, красивая, работящая женщина, которая может жонглировать несколькими вещами одновременно, преуспеть как в любви, так и на работе.

\section{Summary}

Notions "concept" and "linguocturology" are tightly connected with each other and go hand in hand, as in domestic as in modern linguistics. Linguculrological concept "woman" is reflected in modern novels of Sophie Kinsella by creating a definite image of modern woman in contemporary society. This concept is verbalized by different lexical units which contain particular aspects of the concept and which differ in every novel. These lexical units represent a definite aspect of the concept "woman" in its depiction. For instance, both novels "The secret dreamworld of a shopaholic" and "The undomestic goddess" find dynamics of this concept by verbalization of such aspects like "character traits", "work", "love" and "friendship" where the latter two help to expand and develop the main character. 


\section{Литература}

Антропов, В. В., Бурдуковская, Е. А. Лингвокультурный концепт «семья» в текстах специализированного журнала «Батя»: методологический и практический аспекты исследования аксиосферы СМИ. Знак: проблемное поле медиаобразования. 2013 (11/1), с. 67-74.

Карасик, В. И. Языковый круг: личность, кониептыл, дискурс. Москва: Гнозис, 2004.

Петлицкая, В. П., Уланович, О. И. Вербализация концепта «страх» в готическом романе. In: Уланович, О. И. (ed.) Лингвистическая теория иобразовательная практика: сборник научных статей. Минск: Издательский центр БГУ, 2014, с. 207-215.

Попова, 3. Д., Стернин, И. А. Когнитивная лингвистика. Москва: АСТ, ВостокЗапад, 2007.

Рудакова, А. В. Когнитология и когнитивная лингвистика. Воронеж: Истоки, 2004.

Степанов, Ю. С. Константы: Словарь русской культурыл. Москва: Академический проект, 2004.

Kinsella, S. The secret dreamworld of a shopaholic. London: Transworld, 2012.

Kinsella, S. The undomestic goddess. London: Black swan, 2006. 